\title{
A REFORMA POLÍTICA, A PROPOSTA DE EMENDA CONSTITUCIONAL 36 DE 2016 E OS PRINCÍPIOS CONSTITUCIONAIS
}

\section{THE POLITICAL REFORM, THE PROPOSAL FOR CONSTITUTIONAL AMENDMENT 36 OF 2016 AND THE CONSTITUTIONAL PRINCIPLES}

\author{
Maria Lírida Calou de Araújo e Mendonça \\ Pós-Doutora em Direito Tributário pela Universidade de Santa Catarina (UFSC). Doutora \\ em Direito pela Universidade Federal de Pernambuco (UFPE). Mestre em Direito pela \\ Universidade Federal do Ceará (UFC). Professora titular do programa de pós-graduação \\ strictu sensu - mestrado e doutorado - em Direito Constitucional e do curso de graduação \\ em Direito da Universidade de Fortaleza (UNIFOR/CE). Coordenadora e professora do \\ curso de graduação em Direito do Centro Universitário Católica de Quixadá \\ (UNICATÓLICA). Coordenadora-chefe do Grupo de Estudos e Pesquisas em Direito \\ Administrativo e Tributário (GEPDAT). E-mail: liridacalou@unifor.br
}

Luciano Tonet

Doutorando e Mestre em Direito Constitucional Público e Teoria Política pela pela Universidade de Fortaleza (UNIFOR/CE). Professor da Faculdade Integrada da Grande Fortaleza (FGF). Promotor de Justiça - Procuradoria Geral de Justiça do Ceará (PJ/CE), atuando na área da infância e juventude. E-mail: lucianotonet@ hotmail.com

Recebido em: 06/04/2017

Aprovado em: 16/07/2017

Doi: $10.5585 /$ rdb.v17i7.648

RESUMO: As discussões sobre as reformas políticas são uma constante no Brasil. Este trabalho analisa a Proposta de Emenda Constitucional n. 36 de 2016, em consonância com os postulados da razoabilidade, proporcionalidade e princípios constitucionais e o interesse público invocado para justificar estas propostas de mudanças legislativas. A metodologia de pesquisa é bibliográfica, qualitativa e documental. $\mathrm{O}$ objetivo geral é analisar a viabilidade das mudanças trazidas pela proposta de emenda constitucional e a argumentação possibilitada pelos postulados da razoabilidade, proporcionalidade e princípios. O objetivo especifico é verificar se a desconsideração a estes princípios e postulados pode violar a Constituição, a Democracia e a República. O trabalho foi dividido em três tópicos. No primeiro, trata das notas da reforma política e observância dos princípios constitucionais. No segundo, do princípio da moralidade como indicador da reforma política. No terceiro, a razoabilidade e a proporcionalidade das propostas de emenda constitucional e o interesse público.

Palavras-Chave: Reforma Política. Princípios Constitucionais. Emenda Constitucional.

ABSTRACT: Discussions on political reforms are a constant in Brazil. This paper analyzes the Proposal for Constitutional Amendment n. 36 of 2016, $n$ line with the postulates of reasonableness, proportionality and constitutional principles and the public interest invoked to justify these proposals for legislative changes. The research methodology is bibliographical, 
qualitative and documentary. The general objective is to analyze the feasibility of the changes brought by the proposed constitutional amendment and the arguments made possible by the postulates of reasonableness, proportionality and principles. The specific objective is to verify that disregard of these principles and postulates may violate the Constitution, Democracy and the Republic. The work was divided into three topics. In the first, it deals with the notes of political reform and observance of constitutional principles. In the second, the principle of morality as an indicator of political reform. In the third, the reasonableness and proportionality of the proposals for constitutional amendment and the public interest.

Keywords: Political reform. Constitutional principles. Constitutional amendment.

SUMÁRIO: Introdução; 1. Notas da reforma política e a necessária observância aos princípios constitucionais; 2 . O princípio da moralidade como indicador da viabilidade da reforma política; 3. A razoabilidade e a proporcionalidade das propostas apresentadas; $3.1 \mathrm{O}$ interesse público das propostas apresentadas; Conclusão; Referências Bibliográficas.

\section{INTRODUÇÃO}

Em tempos de denúncias de corrupção, apropriação indevida de valores ou bens do patrimônio público, ou, ainda, a malversação pela má administração dos bens públicos, o tema da reforma política ressurge. As análises quanto a Ação Penal n. 470, conhecida como "mensalão" e que tramitou no Supremo Tribunal Federal e a própria Operação "lava jato", têm contribuído para isto. Mas qual a reforma política que se pretende, o que se quer modificar? Estas mudanças são para atender aos princípios da administração pública insculpido no art. 37, da Constituição Federal, de 5 de outubro de 1988? Caso positivo, estas propostas por si mesmas atendem aos referidos princípios?

O que se pretende é a discussão quanto a aplicação dos princípios constitucionais da administração pública nas propostas de emenda constitucional. Isto é, para moralizar a administração pública, conferindo-lhe mais eficiência e transparência, as ainda propostas de reforma devem se adequar aos princípios constitucionais, sob pena de um retorno inaceitável a célebre frase hobbesiana de que os fins justificam os meios.

Pretende-se no presente trabalho estudar algumas das propostas de reforma política trazidas pela PEC 36 de 2016, em trâmite, e à partir das mesmas discutir se atendem e respeitam aos postulados e princípios que regem a administração pública, uma vez que o seu sentido é o de corrigir e reformar para conferir maior eficiência a todo o ordenamento jurídico.

No primeiro tópico, abordam-se as reformas políticas, seu conteúdo e seus reflexos nos poderes da república bem como na administração pública direta e indireta, portanto, o fato de observarem os princípios constitucionais. Apresentam-se as principais mudanças trazidas pela Proposta de Emenda Constitucional $\mathrm{n}^{\mathrm{O}} 36$, de 2016, com referência a análise semelhante feita pelo Supremo Tribunal Federal em 2006, quando foram analisados dispositivos que haviam alterado a Lei dos Partidos Políticos (Lei ${ }^{\circ}$ 9.096, de 19 de setembro de 1995) e os entendido como inconstitucionais, a cláusula de barreira entre eles, por exemplo. O necessário respeito aos princípios constitucionais e aos postulados como o da proporcionalidade e o da razoabilidade, portanto.

No segundo tópico, estuda-se o princípio da moralidade como indicador das possibilidades das mudanças legislativas. Analisa-se a posição do referido princípio no texto constitucional, os valores e dispositivos a ele relacionados. Coloca-se como residual e incidindo simultaneamente com os da impessoalidade, neutralidade, imparcialidade, objetividade, publicidade entre outros.

$\mathrm{Na}$ terceiro tópico, analisa-se os postulados da razoabilidade e da proporcionalidade em 
relação as propostas que a PEC 36 de 2016 pretende modificar. Para tanto, observa-se a conceituação de postulado, seu objetivo e momento de incidência, bem como a diferenciação com os princípios. Em subtópico, analisa-se o interesse público invocado na referida proposta de mudança legislativa e se realmente é um interesse privilegiado, que se deve sobrepor dogmaticamente.

Portanto, o presente estudo tem como objetivo geral, a apresentação e análise das propostas de reformas trazidas pela PEC 36 de 2016 e possibilidade disto ser feito com a argumentação possibilitada pelos postulados da razoabilidade, proporcionalidade e os princípios constitucionais. O objetivo especifico é o verificar se a hipótese de que a referida proposta não atende aos postulados e princípios constitucionais a torna inconstitucional por violar os fundamentos da Constituição Federal. A metodologia de pesquisa é bibliográfica, qualitativa e documental,

\section{NOTAS DA REFORMA POLÍTICA E A NECESSÁRIA OBSERVÂNCIA AOS PRINCÍPIOS CONSTITUCIONAIS}

A reforma do Estado pode se dar sob diferentes perspectivas, com conteúdos político, econômico, jurídico e técnico. A perspectiva política se refere as ideias e diretrizes fundantes da Reforma do Estado; a econômica, ao modo de condução econômica e aos meios de produção; a jurídica, aos instrumentos e procedimentos de atuação do poder para a reforma e a técnica, explica a estratégia do Estado (MENEN e DROMI, 2007, 29). Observa-se que determinadas propostas alcançam direta ou indiretamente todas ou a maioria destas perspectivas. Quanto ao sentido da reforma Menen e Dromi (2007, p. 30) escreveram que as reformas não são estáticas, nem abstratas e possuem um sentido histórico, mas respeitam uma dinamicidade, concretude e as circunstâncias temporais. Assim, ocorrem para atualizar e transformar conforme os reclamos sociais, políticos e econômicos da comunidade nacional.

O Poder Legislativo deve participar com o Executivo na concretização dos objetivos e políticas do Estado. O Legislativo representa a soberania do povo e seu poder se concretiza na Lei. Desta forma, deve retirar seu fundamento da Constituição Federal, dos seus princípios, normas e interpretação conforme o texto. Portanto, as reformas do Estado, entre as quais se inclui a reforma política traz a reforma do direito ${ }^{1}$.

Dromi (2007, p. 83) também escreveu sobre a vinculação do sistema de Direito Administrativo ao Sistema Constitucional, sendo no campo do direito administrativo que se realiza a "categorização jurídica do universo político, seguindo os parâmetros do ordenamento constitucional". Desta forma, há no direito constitucional postulados, princípios e regras administrativas que devem nortear além do cidadão, mas principalmente o homem público ${ }^{2}$.

Segundo Dromi (2007, p 130) "a atuação de todos os órgãos estatais deve ter correspondência com as previsões constitucionais preservando a constitucionalidade da ordem normativa", afirma, ainda, que este controle constitucional é feito pelo Poder Judiciário, sendo que a própria administração possui a faculdade de exercê-lo no exame da validade da norma em relação à Constituição.

Loewenstein (1986, p. 175) quando trata das Constituições difíceis de se modificar cita as mais antigas como da Bélgica e dos Países Baixos. O autor entendia que os motivos para a estabilidade constitucional estaria tanto na extraordinária dificuldade a que está submetida qualquer reforma constitucional, quanto e, sobretudo, no que a prática estatal conseguiu efetuar

\footnotetext{
${ }^{1}$ Miragem (2011) escreve sobre o necessário respeito destas reformas ao direito administrativo, especialmente ao constitucional.

2 "[...] No entanto, a fissura e a quebra produzidos no sistema de Direito constitucional, desbordado pela globalização, a internacionalização e a integração, com a reformulação dos valores e do ordenamento jurídico constitucional, ocasionam os vacilos que se verificam no sistema de Direito Administrativo"(DROMI, 2007, p. 85).
}

Revista de Direito Brasileira | São Paulo, SP | v. 17 | n. 7 | p. 76 - 89 | Mai./Ago. 2017 
por meio de mutações constitucionais. Assim, a acomodação das modificações sociais, não exigiria uma reforma constitucional. Também, isto produziria no povo e nos detentores do poder um profundo respeito frente a Constituição, um sentimento constitucional, lembrando a mitologia constitucional para os norte-americanos, isto é, que a Constituição para os norte-americanos é sagrada.

Com estas premissas, pode-se ingressar no estudo da Proposta de Emenda à Constituição (PEC) $n^{\circ}$ 36, de 2016. Mas, não sem antes alertar para a colocação feita por Saldanha (2000, p. 137) quando tratava da supremacia da Constituição, tendo escrito que "[...] mesmo as normas constitucionais provenientes do legislativo ordinário - as emendas, por exemplo - possuem espécie diferente, já pelo conteúdo, pois ferem matéria mais alta, já pela forma." Isto em um pensamento mais do século XIX e, portanto, que preconizava a supremacia da Constituição, mesmo em virtude de suas posteriores emendas, em virtude de um pensamento constitucional ligado ao titular do Poder Constituinte originário.

Com estas observações, pode-se analisar a proposta aprovada pela Comissão de Constituição e Justiça do Senado Federal, que prevê uma cláusula de desempenho aos partidos políticos e que vem sendo interpretado pela imprensa como a limitação de partidos políticos. $\mathrm{Na}$ referida proposta os partidos deverão obter uma quantidade mínima de votos para o acesso ao fundo partidário, estrutura própria no congresso e propaganda eleitoral no rádio e televisão, isto a partir de 2018.

Conforme a referida proposta os partidos somente poderão atuar no Congresso se obtiverem no mínimo $2 \%$ dos votos válidos em todo o país e $2 \%$ dos votos válidos no mínimo em 14 unidades da federação, cumulativamente. De acordo com a PEC, a partir de 2022 esse percentual subiria para 3\%. O resultado prático imediato com a aprovação seria o de que os eleitos por partidos que não alcançarem este percentual deveriam migrar para outros partidos, o que faria surgir o questionamento quanto a fidelidade partidária por fato superveniente, entre outras questões.

Quanto ao tempo de rádio e televisão uma discussão que se tem é a de que partidos pequenos cedem o seu tempo para outros, motivo pelo qual são chamados de "partidos de aluguel", o que ocorre por meio das coligações. Ainda, nesta esteira, a PEC ainda trata das coligações e estabelece que em 2020 será a última eleição em que se admitirá coligações partidárias. Esta é uma mudança substancial, uma vez que muitos candidatos são eleitos em virtude de alcançarem o coeficiente eleitoral, com o benefício da coligação, de votos dados a outros partidos que a compõem.

A discussão quanto a cláusula de barreira foi aprovada em 1995 pelo Congresso Nacional, contudo, o Supremo Tribunal Federal a considerou inconstitucional no ano de $2006^{3}$. Naquela, o percentual era de 5\%, havia diminuição das estruturas físicas na Câmara, além de restringir outros direitos como impossibilidade de se tornarem lideranças, bem como de participação nas comissões e cargos na mesa diretora. Ainda, os partidos perderiam os recursos do fundo partidário e teriam restringidos o tempo de propaganda no rádio e televisão. A proposta, portanto, volta remodelada sendo que os parlamentares que a defendem apostam na necessidade das referida mudanças e na nova composição do Supremo Tribunal Federal ${ }^{4}$.

Em 2006 todos os Ministros do Supremo Tribunal Federal, à época presidido pela Ministra Ellen Gracie, entenderam que a proposta era inconstitucional ${ }^{5}$. O Ministro Marco Aurélio explanou que isto afetaria as fusões dos partidos pequenos, além de prejudicar a

\footnotetext{
${ }^{3}$ Com o julgamento das Ações de Declaração de Inconstitucionalidade (ADIs) n. 1351-3 e 1354-8), ajuizadas, pelo Partido Comunista do Brasil (PCdoB) e pelo Partido Socialista Cristão (PSC), respectivamente.

${ }^{4}$ http://g1.globo.com/politica/noticia/2016/11/senado-analisa-reforma-politica-e-camara-discute-projetoanticorrupcao.html. Também: http://g1.globo.com/Noticias/Politica/0,,AA1379466-5601,00.html

${ }^{5} \mathrm{http} / / / \mathrm{g} 1$. globo.com/Noticias/Politica/0,,AA1379466-5601,00.html
} 
formação de novos partidos ${ }^{6}$. Naquele ano, de vinte e nove partidos somente sete tinham alcançado e/ou ultrapassado a cláusula de barreira. O principal argumento dos partidos menores era o de que havia lesão ao direito das minorias. É certo que a democracia não é simplesmente o governo da maioria, mas o governo da maioria com respeito aos direitos da minoria, sendo que esta deve possuir o direito de voz, de falar e ser ouvida, isto no parlamento.

Outras questões devem ser observadas, tanto as normas constitucionais mais específicas quanto as do art. 17, da Constituição Federal $^{7}$ e que trata especificamente dos partidos políticos. Quanto os princípios constitucionais insculpidos no art. 37 da Constituição Federal, estes são aplicáveis à administração pública da mesma forma que o são para o exercício do Poder Político ${ }^{8}$, uma vez que dele decorrem. Não pode haver interpretação diversa, sem deixar-se de ser coerente. Mas, e quanto a razoabilidade e proporcionalidade ? Da mesma forma, devem ser analisados e respeitados, todo o ordenamento jurídico e as decisões políticas devem, para serem coerentes, ser razoáveis e proporcionais.

Os princípios constitucionais devem ser respeitados inclusive na apresentação e aprovação das propostas de emenda constitucional. Neste diapasão, a análise da moralidade, da proporcionalidade e da razoabilidade são fundamentais. Segundo Ávila ${ }^{9}$ (2005) existem dificuldades na análise e aplicação dos princípios e mais quando se trata da moralidade, eficiência e razoabilidade da administração pública, uma vez que há muita subjetividade, pois referem-se a valores. Por isto, a sua forma de investigação e aplicação são fundamentais em tudo que se refere a administração pública e as políticas públicas, bem como a política propriamente dita e, consequentemente, as suas reformas, uma vez que devem atentar a valores mínimos e por todos

${ }^{6}$ Decisão da ADI 1351: “O Tribunal, à unanimidade, julgou procedente a ação direta para declarar a inconstitucionalidade dos seguintes dispositivos da Lei $\mathrm{n}^{\circ}$ 9.096, de 19 de setembro de 1995: artigo 13; a expressão "obedecendo aos seguintes critérios", contida no caput do artigo 41; incisos I e II do mesmo artigo 41; artigo 48; a expressão "que atenda ao disposto no art. 13", contida no caput do artigo 49, com redução de texto; caput dos artigos 56 e 57, com interpretação que elimina de tais dispositivos as limitações temporais neles constantes, até que sobrevenha disposição legislativa a respeito; e a expressão "no art. 13", constante no inciso II do artigo 57. Também por unanimidade, julgou improcedente a ação no que se refere ao inciso II do artigo 56. Votou a Presidente, Ministra Ellen Gracie. Ausente, justificadamente, o Senhor Ministro Joaquim Barbosa. Falaram, pelos requerentes, Partido Comunista do Brasil - PC do B e outros, o Dr. Paulo Machado Guimarães e, pelo Partido Socialista Brasileiro PSB, o Dr. José Antônio Figueiredo de Almeida. Plenário, 07.12.2006." Disponível em: < http://www.stf.jus.br/portal/processo/verProcessoAndamento.asp?incidente=1625725 $>$. Acesso em 29.11.2016, as $11 \mathrm{~h}$.

${ }^{7}$ Art. 17. É livre a criação, fusão, incorporação e extinção de partidos políticos, resguardados a soberania nacional, o regime democrático, o pluripartidarismo, os direitos fundamentais da pessoa humana e observados os seguintes preceitos: I - caráter nacional; II - proibição de recebimento de recursos financeiros de entidade ou governo estrangeiros ou de subordinação a estes; III - prestação de contas à Justiça Eleitoral; IV - funcionamento parlamentar de acordo com a lei; $\S 1^{\circ}$ É assegurada aos partidos políticos autonomia para definir sua estrutura interna, organização e funcionamento e para adotar os critérios de escolha e o regime de suas coligações eleitorais, sem obrigatoriedade de vinculação entre as candidaturas em âmbito nacional, estadual, distrital ou municipal, devendo seus estatutos estabelecer normas de disciplina e fidelidade partidária. (Redação dada pela Emenda Constitucional $\mathrm{n}^{\circ}$ 52, de 2006); $§ 2^{\circ}$ Os partidos políticos, após adquirirem personalidade jurídica, na forma da lei civil, registrarão seus estatutos no Tribunal Superior Eleitoral; $\S 3^{\circ}$ Os partidos políticos têm direito a recursos do fundo partidário e acesso gratuito ao rádio e à televisão, na forma da lei; $\S 4^{\circ}$ É vedada a utilização pelos partidos políticos de organização paramilitar.

${ }^{8}$ Barroso (2012) e Moreira Neto (2012) sobre a Constitucionalização do Direito Administrativo e de seus princípios, acabam por demonstrar que não existem dúvidas quanto a este entendimento. Neste sentido Moreira Neto (2012, p. 17) escreveu que: "[...] com o neoconstitucionalismo, inverteu-se esse velho paradigma, que garantia a irresponsabilidade do gestor público de modo que com o reconhecimento da força normativa das normas constitucionais, tanto as normas preceptivas como as principiológicas passararam a vincular juridicamente o exercício de todas as funções estatais e, consequentemente, constitucionalizaram a definição política $e$ a administração dos interesses públicos".

${ }^{9}$ AVILA, Humberto B. Moralidade, Razoabilidade e Eficiência na Atividade Administrativa. Revista Eletrônica de Direito do Estado. N. 4 Out.-Nov-Dez de 2005. Salvador, Bahia, pp. 01-25. 
$\operatorname{aceitos}^{10}$.

Em seus estudos Ávila (2005) apresenta os princípios como normas imediatamente finalísticas, que visam um estado ideal. A propósito, este é o sentido dos princípios, servirem de norte para o agir dentro da sociedade, ou daquele grupo de pessoas que se identificam, em determinado momento histórico. Os princípios insculpidos no art. 37, da Constituição Federal, prescrevem a submissão da administração pública direta ou indireta de todos os Poderes dos Entes Federativos (União, Estados, Municípios e Distrito Federal) aos princípios da administração pública, legalidade, impessoalidade, moralidade, publicidade e eficiência. Portanto, facilmente se aceita que o Poder Legislativo em suas atividades administrativas deva respeitar referidos princípios, o que também deve ser estendido às suas atividades legiferantes, como também observou Di Pietro (2012) ${ }^{11}$. As atividades dos parlamentares, portanto, nada mais são que um prolongamento desta obrigatoriedade, devendo-se atentar à Constituição Federal e às leis, sem procurar beneficiar ilícita ou ilegalmente determinado grupo de pessoas. Isto é, o Poder Legislativo deve ser impessoal; agir dentro do que se espera da moral, com atos publicizados e eficientes.

\section{O PRINCÍPIO DA MORALIDADE COMO INDICADOR DA VIABILIDADE DA REFORMA POLÍTICA}

A história apresenta uma série de continuidades dominantes, as quais simplificam, demasiadamente, os meios de exploração do constitucionalismo, e que desconsideram, por si sós, as diferenças entre os tipos de sociedades. Destaca Figueiredo (2015, p. 32) que, assim, esta mesma desconsideração pode emprestar alicerces e analogias para quadros generalizados e avessos a retratos detidos, complexos e minuciosos sobre as sociedades modernas.

Qualquer atividade desenvolvida por qualquer dos Poderes da República ou mesmo pela administração pública nos segundos e demais escalões exigem um comportamento probo do homem público de forma mais transparente que para qualquer particular e por razões óbvias. Este é o ideal, o que se espera e neste mundo do dever ser surge o princípio da moralidade.

$\mathrm{O}$ princípio da moralidade ${ }^{12}$ exige do homem público, principalmente, condutas sérias, motivadas e transparentes. Está previsto fundamentalmente no art. 37, da Constituição Federal como visto, contudo, pode-se observá-lo em todo o texto constitucional. Ávila (2005) observou que o princípio da moralidade está contido nos valores fundamentais, da dignidade, trabalho, livre iniciativa, isto é, nos arts. $1^{\circ}, 3^{\circ}$ e $5^{\circ}$, da Constituição Federal de 5 de outubro de 1988. Afirma, também que o referido princípio institui um modo objetivo e impessoal de acordo com o Estado Democrático de Direito (art. 10), separação de poderes (art. $2^{\circ}$ ) e legalidade (art. $5^{\circ}$ e 37); além de criar procedimentos, uma vez que universaliza a jurisdição (art. $5^{\circ}$, inc. XXXV), proíbe

\footnotetext{
${ }^{10}$ Barroso (2012, p.63) escreve que com a constitucionalização do Direito Administrativo e com evidência da dignidade da pessoa humana a relação entre administração e administrados mudou e destaca que não há mais aquela ideia de supremacia do direito público, mas os direitos privados recaem sobre a proteção constitucional, exigindo ponderações; o princípio da legalidade se converte em da juridicidade a possibilidade de controle do mérito administrativo.

11 "Com efeito, o primeiro passo no sentido dessa evolução foi dado pela Lei Fundamental da República Federal da Alemanha, promulgada em 08.05 .49 , quando, no art. $30, \S 3^{\circ}$, preceitua que 'o poder legislativo está vinculado à ordem constitucional; os poderes executivo e judicial obedecem à lei e ao direito'. O que se objetiva é a obediência não só à lei, em sentido formal, mas a todos os valores e princípios que estão na base do ordenamento jurídico e que imprimem conteúdo material à lei.”

${ }^{12}$ Conforme Moreira Neto (2012, p. 19) quando trata da orientação ética trazida pelo neoconstitucionalismo escreveu que: "Esta última característica a ser examinada, entre outros paradigmas que poderiam ser lembrados, foi, por longo tempo, excluída das cogitações do Direito, para retornar revigorada no neoconstitucionalismo. E veio, não apenas como um reforço da regra moral comum, por ser indissociável do Direito, como para introduzir a regra moral política, que se considera implícita na cláusula democrática."
} 
provas ilícitas, prevê remédios constitucionais (mandados de segurança, habeas corpus, ação popular, por atos contrários à moralidade e ímprobos). Além disto, na Constituição quando se observa os requisitos para o ingresso na função pública, a necessidade de concurso público (art. 37, II), a vedação de acumulação de cargos (art. 37, XVI), proibição de autopromoção (art. 37 , XXI, $\S 1^{\circ}$ ).

Também, a necessidade de demonstração de idoneidade moral ou reputação ilibada para ocupar os cargos de Ministro do Tribunal de Contas (art. 73), do STF (art. 101), do STJ (art. 104), do TSE (art. 119), do TRE (art. 120). A idoneidade moral requer naturalidade brasileira (art. 12), proibição de reeleição por violação à moralidade (art. 14). Institui vários mecanismos de controle da atividade administrativa, inclusive mediante o controle dos atos administrativos pelos tribunais de contas (art. 70). Nestes casos, trata-se da moralidade administrativa, que em virtude de seu caráter residual e considerando os dispositivos expressos e citados, sequer precisa ser invocada, é inerente. O servidor público e os titulares de poderes devem agir rigorosamente dentro de um padrão de conduta que lhe exigem ser sério, motivar seus atos e ser objetivo.

Para Ávila (2005) o princípio da moralidade é peculiar, porque funciona de modo residual. Na atividade administrativa incidem, simultaneamente, vários princípios, como a impessoalidade, ou neutralidade, a imparcialidade e objetividade, publicidade, transparência, legalidade, igualdade, entre outros. Quando estes forem infringidos, a moralidade também o será, o que denomina de superposição de incidência.

\section{A RAZOABILIDADE E A PROPORCIONALIDADE DAS PROPOSTAS APRESENTADAS}

Ávila (2005, p. 8) diferencia postulados de princípios. Os princípios são normas, uma vez que positivados. Os postulados são metanormas, ou normas em segundo grau, e estabelecem a estrutura de aplicação das demais normas e princípios. O referido autor considera a razoabilidade como postulado e como consequência é que se pode afirmar sobre a violação do postulado da razoabilidade, proporcionalidade e eficiência. Postulados diferem de sobreprincípios como os do Estado de Direito ou devido processo legal, uma vez que situam-se no mesmo nível das normas.

Alexy $(2008$, p.116) refere-se a princípios e a máxima da proporcionalidade, não nomeia de postulado, mas assim o considera. Para o autor a existência dos princípios exige a máxima da proporcionalidade, que é caracterizada pela presença de três requisitos: a adequação, a necessidade (meio menos gravoso) e a proporcionalidade em sentido estrito (sopesamento propriamente dito).

Postulados normativos aplicativos são deveres estruturantes de aplicação de outras normas. O funcionamento dos postulados difere dos princípios ou das regras. Princípios estabelecem um estado ideal de coisas, prescrevem indiretamente comportamentos. Os postulados não impõe a promoção de um fim, mas estruturam a aplicação do dever de promover um fim; não prescrevem indiretamente um comportamento, mas um raciocínio e argumentação relativamente às normas que prescrevem indiretamente comportamentos. As regras descrevem comportamentos devidos ou características de poder. (ÁVILA, p. 9).

A razoabilidade ${ }^{13}$ estrutura a aplicação de outras regras e princípios, sendo usada em vários sentidos: razoabilidade de uma alegação, interpretação, de uma restrição, de um fim legal,

\footnotetext{
${ }^{13}$ Importante a observação feita por Barroso (2012, p. 60) quando escreve sobre os cuidados para se evitar o uso abusivo da discricionariedade judicial, mas que serve a todos os poderes, tendo consignado que "[...] princípios como dignidade da pessoa humana, razoabilidade e solidariedade não são cheques em branco para o exercício de escolhas pessoais e idiossincráticas." Quanto a discricionariedade, também FREITAS (2007), que a estuda como possível de revisão pelo Poder Judiciário, não havendo nenhuma "imune a controle", nem cujo "controle seria defeso ao Poder Judiciário".
} 
da função legislativa entre outros sentidos. Ávila (2005) escreve que na sua análise deve-se ter em vista: primeiro, a relação das normas gerais com as do caso concreto; segundo, é utilizada também como diretriz que exige a vinculação das normas jurídicas com o mundo a que elas se referem e terceiro, é utilizada como diretriz que exige a relação de equivalência entre duas grandezas. Assim, o razoável deve estar de acordo com as circunstâncias fáticas. Deve ser analisada de acordo com o que se pode esperar da boa-fé, isto é, dentro da normalidade.

A razoabilidade deve ser verificada tanto nas Leis existentes, quanto nos projetos de Lei, mais ainda quando se revestem de Projetos de Emenda Constitucional, em virtude do âmbito de abrangência, do critério de diferenciação (entre particulares e servidores públicos, por exemplo, neste ponto prerrogativa não é arbitrariedade ${ }^{14}$ ). Também, a medida adotada deve ser razoável com o critério que a dimensiona. Neste sentido, Ávila (2005, p. 17) tratou da razoabilidade como dever de harmonização do direito com as condições externas, um dever de congruência. Para tanto, citou o exemplo de uma lei estadual que instituiu o adicional de férias de um terço para os inativos, tendo sido considerada sem causa e sem o coeficiente de razoabilidade. Somente trabalhadores possuem o direito de adicional de férias, porque as gozam. Segundo o Supremo Tribunal Federal ${ }^{15}$, nos julgamentos como estes, o legislador elege uma causa insuficiente ou ineficiente para atuação estatal, violando a exigência da vinculação à realidade. Também, que os princípios do Estado de Direito (art. $1^{\circ}$ ) e o do devido processo legal (art. $5^{\circ}$, IV) impedem razões arbitrárias e, portanto, contrárias à realidade.

Importante, ainda, frisar a diferença entre a razoabilidade e a proporcionalidade. A proporcionalidade pode ser da mesma forma que a razoabilidade vista como postulado, de acordo com a visão de Ávila (2005). Para ser proporcional deve haver uma relação causal entre meio e fim, o que diferencia a proporcionalidade da razoabilidade, na qual somente se observa se o resultado é razoável, de acordo com os critérios já vistos, isto é, relação entre critério e medida. Binenbojm (2014, p. 32) escreveu que a ponderação proporcional é também entendida como medida que busca otimizar os princípios e valores constitucionais, portanto, desde às leis até a sua aplicação pelo Poder Judiciário e Poder Executivo ${ }^{16}$.

Vistos os postulados ${ }^{17}$, relação entre meio e fim (proporcionalidade) ou entre o resultado e os critérios escolhidos (razoabilidade), segue-se adiante na análise do ato administrativo do

\footnotetext{
${ }^{14}$ Binembojm (2014, p. 95) quanto a isto escreveu: "[...] No que concerne à fundamentação de leis que outorgam privilégios à Administração Pública, a argumentação apresentada é insuficiente. A esse respeito, verifica-se que Medina Osório afirma a possibilidade de controle quanto à outorga de privilégios à Administração Pública, mostrando-se imperiosa uma análise da proporcionalidade e da razoabilidade de tais leis, sob pena de, descumpridos tais postulados, serem elas declaradas inconstitucionais". Binembojm (2014, p. 96) critica, dizendo que se fosse realmente um princípio legitimaria toda e qualquer outorga de vantagem e arremata: "[...] Em síntese: a ideia de supremacia como norma jurídica não se coaduna com os postulados da proporcionalidade e da razoabilidade, que preconizam a cedência recíproca entre interesses em conflito. E cita ainda para justificar o seu posicionamento o estudo de Ávila (2013) para quem o dito "princípio da supremacia do interesse público sobre o particular" não pode ser considerado norma-princípio, nem sob o ponto de vista de conceito, nem de normativo e menos ainda entendido como postulado.

15 Binenbojm (2008, p.11) afirmou que tal qual as Cortes Constitucionais devem buscar a utilização “[...] da ponderação, guiada pelo princípio da proporcionalidade, para superar as regras estáticas de preferência, atuando circunstancial e estrategicamente com vistas à formulação de standards de decisão".

16 "A técnica da ponderação encontra aplicação recente tanto nos países que adotam o sistema de common law, como do sistema continental europeu, qual forma de controle da discricionariedade administrativa e de racionalização dos processos de definição do interesse público prevalente. Nesse processo, os juízos de ponderação deverão ser guiados pelo postulado da proporcionalidade" (BINENBOJM, 2014, p. 32).

${ }^{17}$ Binembojm (2014, p. 100) alia-se a Ávila $(2005,2007$ e 2013) e reconhece o princípio da proporcionalidade como um postulado, tendo escrito que: "o postulado da proporcionalidade, remansosamente reconhecido pela doutrina e jurisprudência como princípio, é condição para a aplicação das normas jurídicas. Tal postulado orienta a interpretação e aplicação de normas no sentido de acomodar os bens jurídicos em jogo, sem que se exclua totalmente um em prol da subsistência do outro. Ou seja, dentre as opções disponíveis, todas serão otimizadas em algum nível. Este é o dever de ponderação, ao qual se liga o postulado da proporcionalidade.
}

Revista de Direito Brasileira | São Paulo, SP | v. 17 | n. 7 | p. 76 - 89 | Mai./Ago. 2017 
titular do poder, para se analisar se foi eficiente. O dever de eficiência trata do modo de agir da administração, da intensidade dos meios adotados para se chegar a um fim. Deve-se ser o máximo eficiente com menos recursos empregados. A partir disto, surgem as variações para a aplicação do princípio, ser eficiente não quer dizer comprar determinado produto pelo menor preço, mas a qualidade do produto deve ser observada. Deve-se atingir o melhor resultado, o melhor produto, com o menor custo, mas deve-se ter em mente que o produto deve atender a todas as expectativas que dele se espera (ÁVILA, 2005, p. 20).

Com tudo isto, constata-se que a proposta de emenda constitucional apresentada (PEC 36, de 2016) viola o postulado da razoabilidade, uma vez que para alcançar o resultado pretendido, qual seja da reforma política e solução da sua crise, não escolheu os critérios adequados, fez com violação aos princípios. Também, viola o postulado da proporcionalidade, já que para superar a crise política propõem uma reforma, um meio, que tornou-se inadequado por violar regras e princípios. Desta forma, não houve o respeito ao correto raciocínio para aplicação correta das normas principiológicas, o que pode ser constatado quando se analisa que a PEC e a violação aos princípios do pluripartidarismo e da participação democrática, previstos constitucionalmente ${ }^{18}$.

Analisando-se as reformas políticas, em especial a proposta acima referida, deve-se fazêlo tendo em vista as regras preexistentes, como as que tratam das técnicas legislativas, além de compatibilizar o conteúdo com os atos normativos já existentes. Também, os princípios (normas finalísticas) e os postulados, nesta ordem. Quanto ao postulado da razoabilidade e o princípio da eficiência, os mesmos exigem um método como visto, não se basta invocá-los de qualquer maneira, deve-se explicar os critérios utilizados (para a razoabilidade), bem como a utilidade dos meios para se chegar ao melhor fim (eficiência ${ }^{19}$ ).

\subsection{O Interesse Público das propostas apresentadas}

O fato da proposta de emenda constitucional possuir a pretensão de resolver a crise política e os problemas que interessa a todos os brasileiros não é suficiente para que se seja apresentada sem atenção aos ditames dos postulados, dos princípios e com violação às demais normas da Constituição Federal. A invocação da superioridade do interesse público a qualquer pretexto não se justifica por si só. Não se pressupõe a superioridade do interesse público como preconizada na obra de Celso Antônio Bandeira de Melo e em muitos dos seus trabalhos e que serviram de critério de interpretação por muitos julgadores ${ }^{20}$.

A superioridade do interesse público sobre o particular, nos moldes constitucionais contemporâneos, dos direitos humanos e fundamentais, do Estado democrático de direito, com a legitimidade democrática e que estrutura o Estado, surgiu com o direito italiano (DI PIETRO,

\footnotetext{
${ }^{18}$ Ávila (2005).

19 "A eficiência ou eficácia administrativa se traduz no dever jurídico de dar satisfação concreta a uma situação subjetiva de requerimento na forma, quantidade e qualidade e com os meios e recursos que resultam mais idôneos para a gestão. A eficiência é também um princípio jurídico do qual se origina para a Administração um dever positivo de atuação conforme as exigências públicas" (DROMI, 2007, p. 248). Neste sentido, Binembojm (2008, p. 21) escreveu que a Reforma do Estado deve ser orientada pelos princípio da eficiência. Barroso (2012, p. 48) escreveu que uma das marcas da atualizada é "[...] a tensão entre eficiência de um lado, e a legitimidade democrática, de outro $[\ldots]$ ".

${ }^{20}$ Ávila $(2007$, p. 2) esclarece que o que se diz denominar de "princípio da supremacia" na verdade é um axioma, um dogma, que deve ser aceito sem contestação, com "pressuposta validade e posição hierárquica no ordenamento jurídico brasileiro permitiram que ele fosse descoberto a priori, sem o prévio exame da sua referencia ao ordenamento jurídico.” Com o qual o autor não concorda, tendo escrito que: “[...] não há uma norma-princípio da supremacia do interesse público sobre o particular no Direito brasileiro. A administração não pode exigir um comportamento do particular (ou direcionar a interpretação das regras existentes) com base nesse 'princípio'. Aí incluem-se quaisquer atividades administrativas, sobretudo aquelas que impõem restrições ou obrigações aos
} particulares"(AVILA, 2007, p. 29).

Revista de Direito Brasileira | São Paulo, SP | v. 17 | n. 7 | p. 76 - 89 | Mai./Ago. 2017 
2005). Trata-se de uma premissa que deve ser analisada com base na proporcionalidade. Não é dogma a ser aceito sem questionamento.

Gustavo Binenbojm (2014, p. 29) trata desta mudança de paradigma, isto é, refuta a concepção de que o interesse público por pertencer aos indivíduos, como membros de um todo social, seria superior a de indivíduos pessoalmente considerados. O conceito de interesse público é muito fluído como lembra Binenbojm (2014, p. 31) e muitas vezes pode estar atrelado realmente a interesse que se opõe a coletividade, e não o desta, motivo pelo qual deve ser analisado e ponderado (conforme a proporcionalidade) com os demais interesses, com o fim de que seja concretizado até o máximo possível de otimização.

Necessário uma pequena digressão histórica quanto a dicotomia do interesse público e privado antes de se prosseguir na análise da proposta. Binenbojm (2014, p. 83) lembra que a concepção de que a sociedade seria mais importante do que o indivíduo remete a uma opção por uma teoria histórica sobre a pessoa e o seu lugar no mundo, especialmente na sua comunidade. Assim, a prevalência dos interesses privados marcaria mais o Estado Liberal e o individualismo. Continua, com a citação das teorias organicistas e utilitaristas. Para o organicismo a sociedade seria mais importante que o indivíduo, isoladamente considerado, conforme teorias e ensinamentos gregos e frisado por Hegel de que no Estado o indivíduo alcançaria a plenitude de seu ser. Segundo o autor, este organicismo hegeliano foi o responsável pelo nazi-fascismo e o comunismo, quando o fundamento da superioridade do interesse público, torna-se totalitário e liberticida. Mas, deve-se ter a consciência de que a razão de ser do Estado é a de coordenar racionalmente a realização dos projetos das pessoas, individualmente consideradas e não os motivos do Estado, usualmente invocados.

A teoria moral do utilitarismo, por outro lado, que poderia ser invocada da mesma forma para justificar o interesse do Estado em face do indivíduo, funda-se em prover os interesses da maioria dos indivíduos, assim considerados. Diferente do organicismo que se funda no bem para todos, o utilitarismo o faz para o maior número de pessoas (BINENBOJM, 2014, p. 86).

No entanto, em que pesem estas justificativas doutrinariamente plausíveis, no Brasil tomaram um rumo completamente equivocado, direcionado para justificar arbitrariedades, em prol do interesse público. Assim, caso se consideradas estas teorias pode-se ver problemas e inconsistências sérias, no Brasil, contudo os problemas tomaram uma proporção ainda maior, em virtude de se considerar qualquer justificativa, mas com o pano de fundo da arbitrariedade. O que se têm é a tentativa de manter o poder, o que antes deveria ser o resultado da soberania popular, passa, assim, a ser estruturante de defesa de oligarquias e que acabam por confundir suas vidas particulares, do privado com o público. Utilizam-se do público, da coisa pública, como se particular fosse e, pior, privando os seus reais titulares de a usufruírem, ao fundamento, do interesse público, por mais inverossímil que isto pareça.

Ademais, é comum a confusão entre público e privado pela doutrina brasileira, Binembojm (2014, p. 91) cita Celso Antônio Bandeira de Mello, que sobrepõe o interesse público (que chama de coletivo) aos particulares. Na mesma esteira o faz citando Maria Sylvia Zanella Di Pietro, que segundo o autor para argumentar acaba por adentrar em campo de princípios diversos como o da impessoalidade e da moralidade, quando a mesma acaba por criticar favorecimentos pessoais e disputas políticas. Com ênfase, esta defesa da supremacia foi feita por Fábio Medina Osório, que Binembojm considera o maior defensor do referido princípio. Mas, a mesma crítica feita a Maria Sylvia Zanella Di Pietro também podem ser atribuídas ao mesmo autor. Assim, a finalidade da Constituição e das leis para o agir da administração pública não é o mero e superficial afastamento dos interesses individuais. (BINEMBOJM, 2014, p. 95).

Barroso (2005, p. vii) expõe que o verdadeiro problema teórico para o direito administrativo é o conteúdo do que deve prevalecer. Ocorre que sob os auspícios de princípio, muita arbitrariedade foi cometida e ainda hoje o é. Para tanto se observar isto, basta uma superficial análise de todo o que se concebeu por coronelismo, patriarcalismo, filhotismo, na 
qual, sob o manto de proteger o povo, protegia-se a si mesmo. Este malsinado "interesse público" passou para a república e posteriormente para o Estado Democrático, por isso, ainda é visto. Leis como a da segurança nacional ${ }^{21}$ possuem arbitrariedades, que embora não convenha aqui analisar, é importante lembrar que se baseia no interesse público, violando direitos particulares, contudo, caso sopesados com aqueles, o particular se sobressairia ${ }^{22}$.

Nelson Saldanha em seu "o jardim e a praça" faz referência a diversos autores que estudaram sobre o papel do espaço público na história, desde a época clássica grega até a contemporaneidade. Contudo, quando menciona Arendt e se filia a seu posicionamento, de certa forma, merece destaque o pensamento de que a sociedade atual, massificada, acaba por destruir as duas esferas, a pública e a privada, pois priva as pessoas do seu lugar no tempo e no espaço em que estão circunscritas, como também de seus próprios e particulares espaços (SALDANHA, 2005, p. 53).

Os homens podem ser privados de seu espaço público de diversas maneiras, mas a mais comum é a usurpação por parte daqueles que detendo o poder, utilizam do público como se deles (privado) fosse. A privação do espaço privado pode ocorrer com o excesso de tributação, desestimulando o consumo para financiar a dita "coisa pública" e o espaço público, citado e distorcido.

Portanto, nas propostas apresentadas, tanto a rejeitada, como esta em trâmite, vê-se a tentativa firmar, fortalecendo ainda mais os grupos políticos que, de certa forma, já vem mantendo uma hegemonia no poder. Assim, àqueles que chegam agora à vida pública e que naturalmente compõem, pelo menos momentaneamente a minoria, ficam privados de ingressar na política e oxigená-la, uma vez que o fazem sem "prestar continência" aos "coronéis"23. O que, propositalmente ou não, demonstra que a PEC além de violar normas principiológicas constitucionais, ainda viola princípios constitucionais implícitos e postulados, como o da razoabilidade e da proporcionalidade. A teoria do discurso jurídico racional, partindo de um ideal, auxilia na visão destes vícios da proposta apresentada, como escreve Alexy (2011, p. 286) "os juristas podem certamente contribuir para a realização da razão e da justiça, mas não podem fazer isto sozinhos. Isto pressupõe uma ordem racional e justa."

Não se pode, com todo o exposto, cogitar-se na presença do interesse público nas propostas apresentas, uma vez que tendem a restringir o acesso ao poder, mesmo que indiretamente, impedindo que se formem pequenos partidos, ou deixar que deixem de existir por falta das condições mínimas, tais como propagandas no rádio ou na televisão, o acesso a fundo partidário, a possibilidade de um instalações dentro do congresso nacional ou, ainda, com a restrição de se tornarem lideranças.

\section{CONCLUSÃO}

As diversas denúncias de malversação de bens e valores públicos, em virtude dos níveis em que se chegou a corrupção e demonstrados em ações como a do "mensalão" e da operação "lava-jato", não são suficientes para justificar uma reforma açodada e na qual não se discutam os reflexos em todos os níveis que a mesma possa atingir.

Com todas as discussões em torno da política, dos processos eleitorais, dos problemas

\footnotetext{
${ }^{21}$ Lei $\mathrm{n}^{\mathrm{o}} 7170$, de 14 de dezembro de 1983.

22 Binembojm (2008, p. 12) neste sentido escreveu: “[...] a emergência de um modelo de ponderação, como critério de racionalidade do direito (e do próprio Estado democrático de direito), servirá de instrumento para demonstrar a inconsistência da ideia de um princípio jurídico (ou um postulado normativo aplicativo) que preconize a supremacia abstrata e a priori do coletivo sobre o individual ou do público sobre o privado.

${ }^{23}$ Utiliza-se o termo "coronéis" em analogia ao que simbolizaram no passado, uma vez que eram os chefes politicos da república velha. O nome, contudo, encontra-se constantemente no linguajar popular, além de reportagens jornalísticas quando querem se referir a pessoas que se consolidaram na vida pública e mesmo envolvendo-se em escândalos e em crimes eleitorais, por exemplo, continuam a ser reeleitos.
}

Revista de Direito Brasileira | São Paulo, SP | v. 17 | n. 7 | p. 76 - 89 | Mai./Ago. 2017 
econômicos gerados pela corrupção e que motivou e tem motivado o dia-a-dia das reformas políticas em todos os níveis dos poderes e da administração pública, surge uma questão que deve ser investigada. Trata-se do fato de que em qualquer tentativa de reforma deve-se ater aos princípios constitucionais que regem a administração pública e que pautam o agir dos legisladores. Ademais, com exigência de que não destoem dos postulados da razoabilidade e da proporcionalidade, que fazem a intermediação entre os valores esperados e as normativas internacionais e discutidas.

As reformas podem ter conteúdos políticos, econômicos, jurídicos ou técnicos, mas excepcionalmente restringem-se a algumas destas áreas, sem grandes reflexos para as demais. As próprias reformas são dinâmicas, merecem correção durante o seu processo. Devem ser analisados os reflexos para os poderes da república, bem como para a administração pública direta e indireta, motivo pelo qual é necessário a observância da aplicação dos princípios da administração pública também para o legislador, uma vez que na função que desempenha de representar o povo, também é o seu servidor.

Observou-se no presente trabalho que as propostas apresentadas como de reforma política, PEC 36, de 2016, são na verdade, mais reformas eleitorais, em virtude do seu conteúdo, tais como a limitação de partidos políticos que obtiveram poucos votos, com consequências como a diminuição ou mesmo a proibição de acesso ao fundo partidário, ao uso da estrutura no congresso destinado a partidos políticos e a restrição à propaganda eleitoral no rádio e na televisão.

Proposta semelhante foi afastada pelo Supremo Tribunal Federal em 2006, quando o Ministro Marco Aurélio chegou a afirmar que limitar os partidos políticos menores, da forma que fora posta, seria condená-los à morte por inanição. Na verdade, mais do que isso, coloca-se em cheque a própria democracia, considerando que esta não é o governo da maioria, mas o desta com o respeito as opiniões da minoria. Para tanto, a minoria deve estar representada, deve ter voz, deve estar no parlamento. A alegação de que as minorias servem como partido de aluguel, não é de todo verdade e não é amparada em pesquisas científicas, uma vez que basta analisar o surgimento de muitos dos pequenos partidos, para se observar a solidez ideológica dos mesmos.

Portanto, constatou-se que as propostas apresentadas deveriam ser analisadas a luz dos postulados da razoabilidade e proporcionalidade, bem como dos princípios que regem a administração pública. Contudo, sequer passariam pelos princípios consagrados na Constituição Federal, mas mesmo assim se fez uma reflexão argumentativa para demonstrar que também não passariam pelos referidos postulados.

Tendo-se observado os princípios constitucionais e sua importância também diferencioos dos postulados e destes também se pontuou a diferença entre o da razoabilidade e o da proporcionalidade. O próprio funcionamento dos postulados é diferente quando comparados aos princípios. Enquanto os princípios procuram estabelecer um estado ideal, um fim, os postulados não o impõe, mas tratam da necessária estrutura da aplicação para promover o fim. Cuidam de um raciocínio e argumentação em relação as normas que prescrevem os comportamentos.

A razoabilidade pode ser usada em vários sentidos, como a de uma alegação, interpretação, restrição de fim legal, e tem em vista a relação das normas gerais com as do caso concreto, bem como torna-se uma diretriz das normas com a realidade, além de uma relação de equivalência entre estas duas realidades. Portanto, deve ser analisada em relação as leis existentes e aos projetos que se quer apresentar. A proporcionalidade significa que deve existir uma relação causal entre meio e fim. Isto é, uma medida que deve otimizar os princípios e interesses Constitucionais, desde a proposição pelo Legislativos até a aplicação pelo Judiciário.

Quanto se analisou as propostas a luz dos princípios, da mesma forma, restou comprovado que não foram respeitados. Ademais, as propostas não atendem ao interesse público. Sob a alegação de protege-lo contra partidos que emprestam suas siglas a outros nas coligações, com o do tempo de campanha daqueles, por exemplo, além de outras questões, como estudado, 
inverteram-se os valores. Com o discurso do interesse público no combate a corrupção e demais fatores já apontados em relação a crise política apontaram-se saídas nada democráticas ou republicanas, com a limitação do exercício da cidadania passiva e com a centralização do poder e do controle da coisa pública ainda mais nas mãos de poucos, o que se torna grave a medida que se observa o aumento de certos privilégios.

Diante do exposto, observou-se que as propostas não atendem ao interesse público, o que pode ser constatado a partir da argumentação conforme os postulados da proporcionalidade e da razoabilidade, além de não estarem alinhados com os princípios implícitos e, principalmente, com os explícitos da Constituição Federal. Afrontam, assim, os próprios fundamentos da Constituição: o regime político democrático e a forma de governo republicana.

\section{REFERÊNCIAS BIBLIOGRÁFICAS}

ALEXY, Robert. Teoria dos Direitos Fundamentais. Trad. Virgilio Afonso da Silva. São Paulo: Malheiros, 2008.

ALEXY, Robert. Teoria da Argumentação Jurídica: A Teoria do Discurso Racional como Teoria da Fundamentação Jurídica. Trad. Zilda Hutchinson Schild Silva. Rio de Janeiro: Forense, 2011.

AVILA, Humberto B. Princípio da Supremacia do Interesse Público sobre o Particular. Revista Eletrônica sobre a Reforma do Estado (RERE). n. 11 Set.-Out.-Nov de 2007. Salvador, Bahia, pp. 01-30. Disponível em: <http://www.direitodoestado.com.br/rere.asp>. Acesso em 05.12.2016.

AVILA, Humberto B. Moralidade, Razoabilidade e Eficiência na Atividade Administrativa. Revista Eletrônica de Direito do Estado. n. 4 Out.-Nov-Dez de 2005. Salvador, Bahia, pp. 01-25. Disponível em: <http://www.direitodoestado.com.br/rere.asp>. Acesso em 05.12.2016.

AVILA, Humberto B. Teoria dos Princípios: da definição à aplicação dos princípios jurídicos. 14a ed. São Paulo: Melhoramentos, 2013.

BARROSO, Luiz Roberto. Prefácio. In. Interesses Públicos vs. Interesses privados: desconstruindo o princípio de supremacia do interesse público. Coord. SARMENTO, Daniel. Rio de Janeiro: Lumen Juris, 2005. pp. vii-xviii.

BARROSO, Luiz Roberto. A constitucionalização do direito e suas repercussões no âmbito administrativo. In Aragão. Alexandre dos Santos de; MARQUES NETO, Floriano de Azevedo (Coord.). Direito administrativo e seus novos paradigmas. Belo Horizonte: Forum, 2012. p. 3163.

BINENBOJM, Gustavo. A Constitucionalização do Direito Administrativo no Brasil: Um Inventário de Avanços e Retrocessos. Revista Eletrônica sobre a Reforma do Estado. N. 13 Mar.Abr.-Mai de 2008. Salvador, Bahia, pp. 01-43.

BINENBOJM, Gustavo. Uma Teoria do Direito Administrativo: Direitos Fundamentais, Democracia e Constitucionalização. 3a. ed. Rio de Janeiro: Renovar, 2014.

BRASIL. Constituição (1988). Constituição da República Federativa do Brasil. Brasília, DF, Senado, 1988.

DI PIETRO, Maria Sylvia Zanella. Da constitucionalização do direito administrativo: reflexos 
sobre o princípio da legalidade e a discricionariedade administrativa. Atualidades Jurídicas Revista do Conselho Federal da Ordem dos Advogados do Brasil. Belo Horizonte, ano 2, n.2, jan./jun.2012. Disponível em:

<http://www.bidforum.com.br/bid/PDI0006.aspx?pdiCntd=80131>. Acesso em: 24 maio 2014.

DI PIETRO, Maria Sylvia Zanella. Inovações no direito administrativo brasileiro. Interesse Público - IP: Belo Horizonte, ano 7, n. 30. Mar./Abr. 2005. Disponível em: http://www.bidforum.com.br/bid/PDI0006.aspx?pdiCnttd=50030. Acesso em 30 jul 2015.

FIGUEIREDO, Eduardo Henrique Lopes de. Revista de Direito Brasileira: Florianópolis, ano 5, vol. 12, 2015. Disponível em: http://www.rdb.org.br/ojs/index.php/rdb/article/download/356/219. Acesso em: 06.04.2017.

FREITAS, Juarez. Discricionariedade Administrativa e o direito fundamental à boa administração pública. São Paulo: Malheiros, 2007.

LOEWENSTEIN, Karl. Teoría de La Constitución. Barcelona: Ariel Derecho, 1986.

MENEN, Carlos e DROMI, Roberto. Reforma del Estado. Buenos Aires: Fundación Centro de Estudios Políticos y Administrativos, 2007.

MIRAGEM, Bruno. A nova administração pública e o direito administrativo. São Paulo: Revista dos Tribunais, 2011.

MOREIRA NETO, Diogo de Figueiredo. Constitucionalização do direito administrativo. Revista da Procuradoria-Geral do Município de Juiz de Fora-RPGJF, Belo Horizonte, ano 2, n. 2, p. 13-23, jan./dez. 2012.

SALDANHA, Nelson. Formação da Teoria Constitucional. 2a ed. Rio de Janeiro: Renovar, 2000.

SALDANHA, Nelson. O jardim e a praça. Rio de Janeiro: Atlântida Editora, 2005. 